\title{
Learning a Behavioral Sequence: An Accessible Challenge for Myrmica sabuleti Workers?
}

\author{
Marie-Claire Cammaerts ${ }^{1} \&$ Roger Cammaerts ${ }^{2}$ \\ ${ }^{1}$ Independent researcher, retired from the Department of Biology of Organisms, University of Brussels, Belgium \\ ${ }^{2}$ Independent researcher, retired from the Natural and Agricultural Environmental Studies Department (DEMNA) \\ of the Walloon Region, Belgium \\ Correspondence: Marie-Claire Cammaerts, Independent researcher, retired from the Department of Biology of \\ Organisms, University of Brussels, Belgium. E-mail: mccammaerts@gmail.com
}

Received: January 14, 2018

Accepted: January 23, 2018

Online Published: January 30, 2018

doi:10.5539/ijb.v10n2p1

URL: https://doi.org/10.5539/ijb.v10n2p1

\begin{abstract}
We aimed to investigate on the ability of the ant Myrmica sabuleti in learning a behavioral sequence. We created two sequences consisting in navigating through five successive elements on the way to the nest, and tried to learn them to foragers. They could progressively learn a sequence for which the different steps were presented in a backward order. Doing so, each exhibited step leaded to an already known step and thus to the reward consisting in finally entering the nest. The ants were unable to learn a behavioral sequence for which the different steps were presented in a forward order. With the latter kind of presentation, each exhibited step leaded to an unknown step and thus not to the reward. Myrmica sabuleti ants learned thus a behavioral sequence when going through operant conditioning and not by using the response to a step as a motivation for responding to the next step. On the contrary, highly evolved mammals (monkey, humans) and birds (parrots) can learn a behavioral sequence according to a backward or a forward chaining, or by being presented with the entire sequence and memorizing, then imitating the different steps.
\end{abstract}

Keywords: memory, nest re-entering, operant conditioning, response chaining

\section{Introduction}

Learning a sequence of acts is an ability detained by several evolved species, above all by some birds and monkeys. Such ability has not yet been researched in ants, which are evolved eu-social hymenoptera. This is why we aimed to make such a research.

There exist three categories of behavioral sequence learning (Pearce, 2008). A. In a 'serial recognition', to obtain a reward, the animal learns to discriminate one sequence of items from other sequences made of the same items but presented in different orders. B. A 'response chaining' ability consists in being finally able to exhibit two or more acts in a given order for obtaining a reward (Balleine, Garner, Gonzalez, \& Dickinson, 1995). C. A 'simultaneous chaining' occurs when an individual is simultaneously confronted to several elements and finally succeeds in selecting each element in a given 'correct' order which leads to a reward (Terrace, 1986). During the latter learning, pigeons and monkeys appear to solve the problem using different learning methods (Terrace, 1987; D'Amato \& Colombo, 1988). A difference of learning method between species seems to exist also for the 'response chaining' ability since some controversy aroused as for the method used by the animals which learn a behavioral sequence during such a chaining experiment. Two theories were proposed to explain the 'response chaining' learning ability (Thvedt, Zane, \& Walls, 1984): (a) a response functioning itself as a stimulus for presenting a subsequent response; (b) a response producing a stimulus (i.e. allowing the apparition of a stimulus) which functions as an 'invitation' to present a subsequent response. These two theories correspond, in fact, to the two ways an animal can be learned a response chaining. The animal can be firstly confronted to the last act to be performed, then to the previous one, then to the still previous one, and so on, and finally to the first act which must be exhibited. The animal can also be confronted to the first act to be given, then to the second one, after that to the third one and so on, and finally to the last one. The first method of learning can be labeled 'backward chaining', and the second method 'forward chaining'. The underlying cerebral learning process may differ between the two kinds of learning methods. Using the 'backward chaining' method, the animal is rewarded after the first presented step (which is in fact the last step of the sequence to be learned). Then, this step functions as a reward for acquiring the previous step. Thereafter, that 
previous step functions as a reward for exhibiting the still previous step. This goes on until the first step of the sequence. Using the 'forward' method of learning, after having learned the first step (which is effectively the first step of the sequence) which leads to a reward, when trained to learn the next step, the animal will be confronted to an unknown second step which is not a reward, and will be obliged to use its first correct response as a stimulation for being incited to make that next step. The same situation occurs when the animal is then confronted to the third step, thereafter in front of the fourth step and so on. The reward appears then only after the animal has successfully performed all the acts of the sequence from the first to the last one.

Trying to learn a behavioral sequence to an animal using each of the two 'response chaining' methods may allow approaching the system used by the animal to learn the sequence, so the cerebral learning process used by that animal for acquiring this chaining ability. In the present study, we tried to learn a behavioral sequence to ants of a given species using each of the two methods. This will brought information on the ants' ability in learning a behavioral sequence, as well as (if the ants detained the ability of learning a sequence) on the physiological underlying process allowing such a learning.

We worked on Myrmica sabuleti Meinert 1861, the biology of which is rather well known since we have examined its ecology, eye morphology, visual perception, conditioning ability, recruitment system, navigation strategy (M.-C. Cammaerts \& D. Cammaerts, 2014). We have also approached the ontogenesis of Myrmica ants' abilities (M.-C. Cammaerts \& R. Cammaerts, 2015a). We also know that these ants can expect the location and the time of food delivery on basis of previous deliveries (M.-C. Cammaerts \& R. Cammaerts, 2016a, 2016b), recognize themselves in a mirror (M.-C. Cammaerts \& R. Cammaerts, 2015b), individually acquire conditioning and imitate (Cammaerts, 2013), solve simple problems (Cammaerts, 2017a), and can acquire new methods in a novel situation (Cammaerts, 2017b), but cannot use sensu stricto tools (Cammaerts, 2018). The present study was thus a further step in our knowledge of Myrmica ants' biology, bringing information on the ants' ability in learning a sequence of behavior, and on the behavioral process(es) they use to learn such a sequence.

\section{Material and Methods}

\subsection{Collection and Maintenance of Ants}

The experiments were made on two colonies of M. sabuleti collected at Rédange (France, Moselle department) in May 2017. They contained about 500 workers, brood and one queen. Each of them was maintained in glass tubes half filled with water, a cotton plug separating the ants from the water. The nest tubes of each colony were deposited in a tray $(34 \mathrm{~cm} \times 23 \mathrm{~cm} \mathrm{x} 4 \mathrm{~cm})$, the borders of which were covered with talc to avoid ants' escaping. The ants were fed with an aqueous solution of sugar given ad libidum in small cotton plugged tubes and with cut Tenebrio molitor larvae (Linnaeus, 1758) given three times per week. Laboratory parameters were optimum for the species: temperature of $20-21^{\circ} \mathrm{C}$, humidity of about $80 \%$, intensity of lighting of 330 lux while working on ants and of 5-120 lux during other time periods, electromagnetic field of $2-3 \mu \mathrm{W} / \mathrm{m}^{2}$. The workers are here often named nestmates, as do researchers on social insects.

\subsection{Preliminary Remark}

1) For comparing the learning of a behavioral sequence by ants in a 'backward chaining' way and in a 'forward chaining' way, we had the choice between two possibilities: learning, using one method, a behavioral sequence to two ant colonies, and learning, using the other method, the same behavioral sequence to two other ant colonies, or learning a sequence to two colonies using one method and learning another sequence, different but identical in difficulties, to these two same colonies. We know the variability in cognitive abilities between colonies, even if they are living on the same area in the field (Cammaerts, 2017c). We thus chose to use twice the two same colonies, and to construct two different behavioral sequences identical in difficulties. 2) The two colonies being experimented at the same time, training one colony in one way, and the other colony in the other way, using thus at the same time two different experimental apparatus, may have leaded to potential handling errors. The two colonies were thus trained, at the same time, using the same method. 3) On the basis of a coin tossing, we proceeded first with the 'backward chaining' way, and then with the 'forward chaining' way. 4) All the experiments were conducted on the ants' foraging area, so on a known area. Each colony had its own apparatus which became familiar to the ants, not only visually, but also odorously since ants may deposit on it their Dufour gland content and cuticular lipids.

\subsection{Experimental Apparatus $n^{\circ}$ 1; First Method of Learning (Backward Chaining)}

Schemas and photos of the apparatus are given in Fig. 1. In fine, for re-entering their nest, the ants should navigate a complex path, being obliged to walk successively on a bridge (part 5), through a prismatic form (part 4), round a barrier (part 3), through a parallelepiped form (part 2), and through a cylindrical form (part 1). The five parts of the 
apparatus were separately constructed in strong semi-transparent paper (Calque satin Canson ${ }^{\circledR} 50-55 \mathrm{~g} / \mathrm{m}^{2}$ ), and could easily be assembled at each appropriate experimental time.

The ants were initially presented with the entire apparatus i.e. made of its 5 parts, tied to the nest entrance. Thereafter, they were learned to navigate the apparatus by being firstly confronted to the last step of the sequence, the cylindrical form (part 1) tied to the nest entrance, then to the parallelepiped form (part 2) tied to part 1, the latter being still tied to the nest entrance, then to the barrier (part 3) set in front of the part 2 tied to the part 1, then to the prismatic form (part 4) into which the barrier was set, and finally to the bridge (part 5) attached to the part 4 tied to the parts 3, 2, 1, so to the entire apparatus. Let us recall that, as stated here above, the part 1 of the apparatus was tied to the nest entrance during each presentation. This essay (I) was made a second time (essay II) for examining if ants retained something of their learning.

\subsection{Experimental Apparatus $n^{\circ}$ 2; Second Method of Learning (Forward Chaining)}

Schemas and a photo of the apparatus are given in Figure 2. In fine, for re-entering their nest, the ants should navigate a complex path, being obliged to navigate successively a cylindrical form containing pieces of rosemary (part 5), a cylindrical form with six black spots (diam $=2 \mathrm{~mm}$ ) (part 4), a prismatic form (part 3), a hexahedral from containing a twist and turn path (part 2), and finally a bridge (part 1). Similarly to the apparatus $n^{\circ} 1$, the five parts of the apparatus $n^{\circ} 2$ were separately constructed in strong semi-transparent paper (Calque satin Canson ${ }^{\circledR}$ $50-55 \mathrm{~g} / \mathrm{m}^{2}$ ), and could easily be assembled at each appropriate experimental time.

The ants were initially presented with the whole apparatus made of its 5 parts, tied to the nest entrance. After that, they were learned to acquire the entire behavioral sequence (i.e. to navigate the 5 parts of the apparatus) by being confronted firstly with the first step of the sequence, the cylindrical form containing pieces of rosemary (part 5) tied to the nest entrance, then with that part 5 and the cylindrical form with six black spots, this part 4 being tied to the entrance, then with the two first parts of the apparatus and the prismatic form, that is the part 3 , tied to the entrance, then to the three first parts of the apparatus and to the hexahedral form containing the twist and turn path, this part 4 being tied to the entrance, and finally with the four first parts of the apparatus and the bridge which was the part 5 tied to the entrance, so with the entire apparatus. This essay (I) was made a second time (essay II) to see if ants could ameliorate their learning score.

\subsection{Assessment of the Ants' Behavior}

During each presentation of each part(s) of the two experimental apparatus, which were made at successive days, the here below explained assessment of the ants' behavior was made.

During 15 minutes, at the end of each minute, the ants present just aside and on the presented parts of the apparatus were counted, as well as those navigating these parts orienting themselves towards the nest entrance. Note that, during this time, a few ants may move in the other direction, but this had no impact on the present assessment. For each count, the 15 numbers obtained for the two colonies were added (Tables 1, 2, 4, 5 columns 3 to 8), and the proportion of ants navigating each presented part among those present were established (Tables 1, 2, 4, 5, columns 4 to 8). For each presentation of one to five parts of the apparatus $n^{\circ} 1$ and $n^{\circ} 2$, the mean proportion of ants correctly navigating the presented parts was established (Tables 1, 2, 4, 5, column 1).

The same assessment as above was then made, for each kind of apparatus presentation and learning method, separately for the first five minutes and the last five minutes of the experiment. Only the mean proportion was here, each time, taken into account (Tables 3, 6, column 2 to 5). The average of the obtained mean proportions was calculated for the first and the last five minutes of the essay, what allowed establishing the increase of learning that occurred between the beginning and the end of the essay (Table 3, 6, column 6).

For each two apparatus, and thus each kind of learning ('backward and forward' chaining), a second essay (II) (including all the presentations: the initial one, and the 1 to 5 parts of the apparatus) was conducted since the following day, in order to examine if the ants retained something of the learning they acquired during the essay I, could ameliorate their learning score, or could finally succeed in somewhat learning the sequence (Tables 2, 5).

The mean proportions of ants correctly navigating the presented parts of the apparatus $n^{\circ} 1$, as well as $n^{\circ} 2$, obtained during the first conducted essay (I) were compared to those obtained during the second conducted essay (II) (to examine if ants better responded during the second experiment) using the non-parametric test of Wilcoxon (Siegel \& Castellan, 1989) with $\mathrm{N}=5$. In the same way, the proportions of ants correctly navigating the presented parts of the apparatus $\mathrm{n}^{\circ} 1$, as well as $\mathrm{n}^{\circ} 2$, obtained during the last five minutes of the experiments were compared to those obtained during the first five minutes of the experiments (to examine if ants learned the sequence in the course of the 15 experimental minutes) using the non-parametric test of Wilcoxon (Siegel \& Castellan, 1989) with $\mathrm{N}=4+4=8$. 


\section{Part 1: cylindrical form}

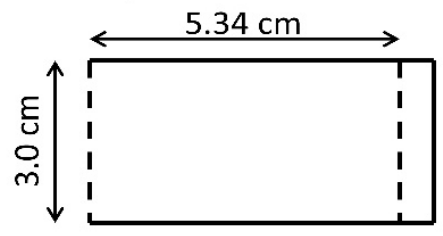

Part 2: parallelepiped form

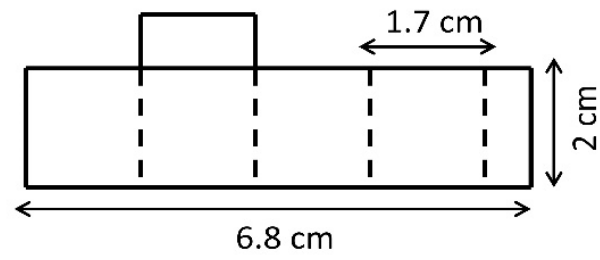

Part 3: barrier

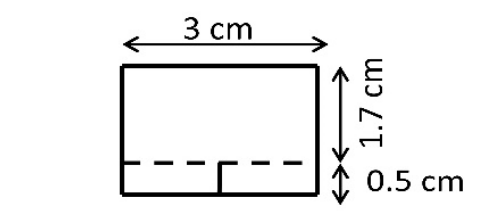

Part 4: prismatic form

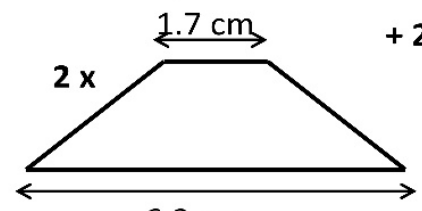

$6.3 \mathrm{~cm}$

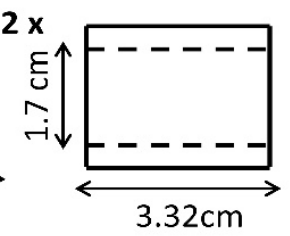

$3.32 \mathrm{~cm}$

\section{Part 5: bridge}
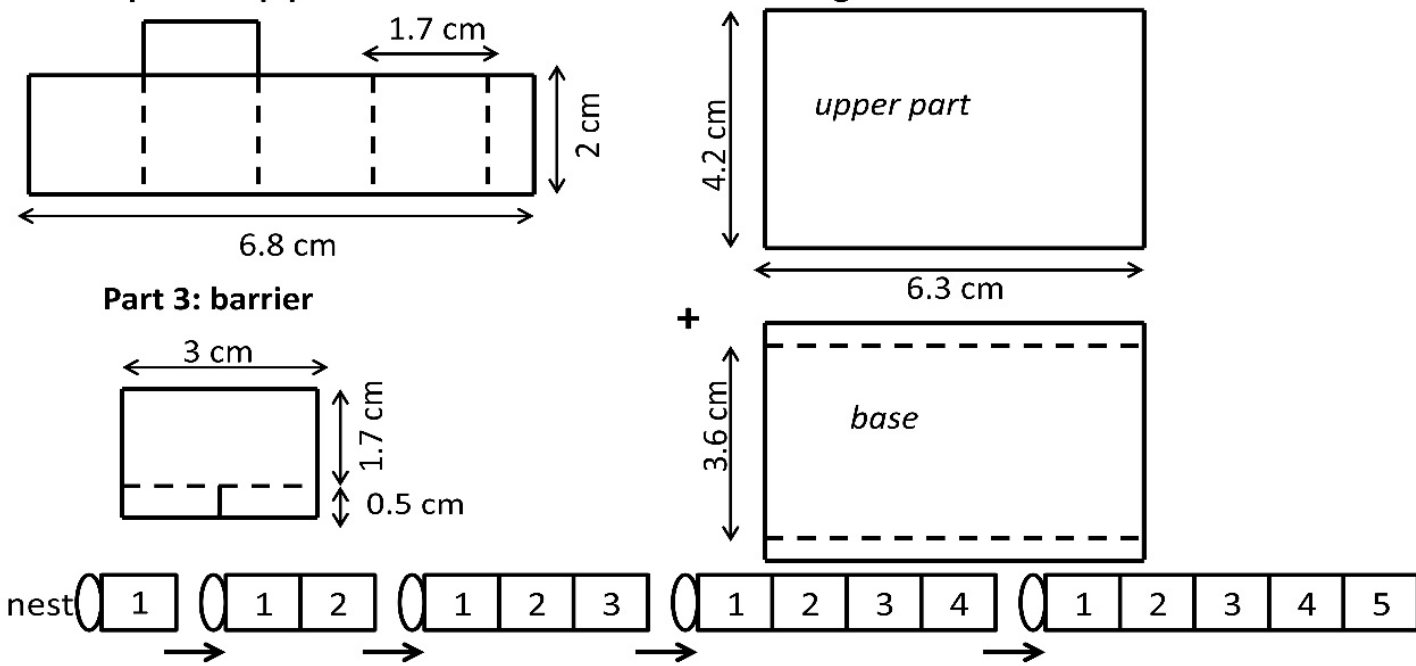

successive experimental presentations of the five parts of the apparatus
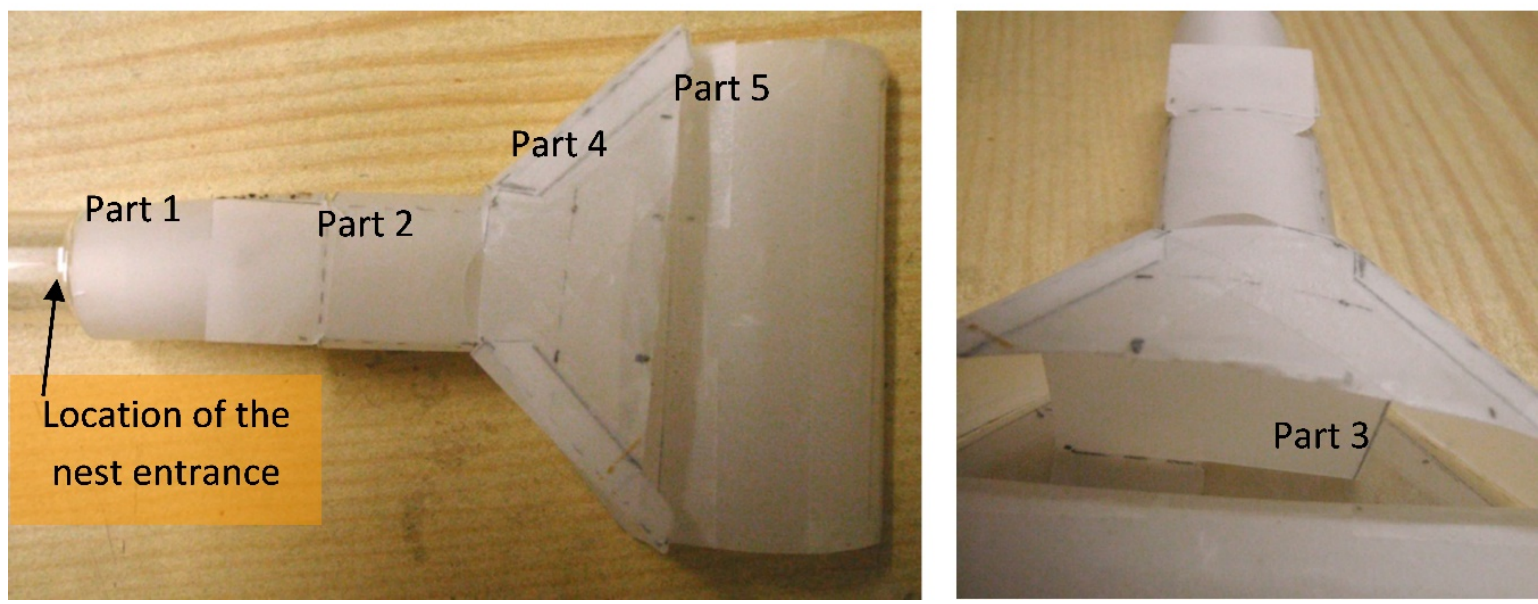

Figure 1. Details of the experimental apparatus $n^{\circ} 1$ which was tied to the nest entrance during the experiment It was made of five parts, and was initially presented to the ants as a whole. Then, its part 1 , parts $1+2$, parts $1+2+3$, parts $1+2+3+4$, and finally parts $1+2+3+4+5$, i.e. the entire apparatus, were successively presented. This enabled to examine if ants could learn, by using a 'backward chaining' method, the behavioral sequence consisting in navigating correctly the five parts of the apparatus, for entering their nest. 


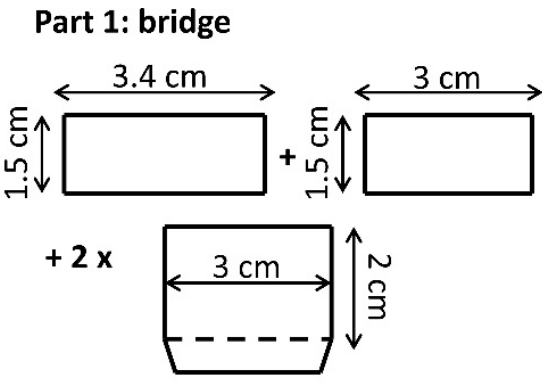

Part 2: hexaedric form

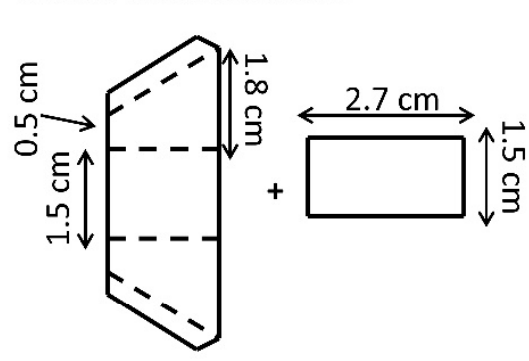

\section{Part 3: prismatic form}

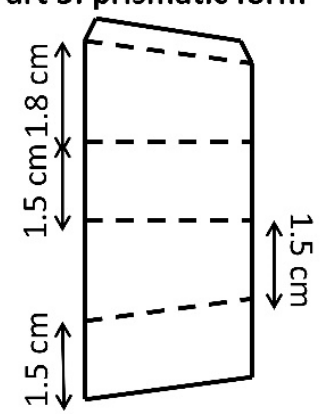

\section{Part 4: cylindric form}
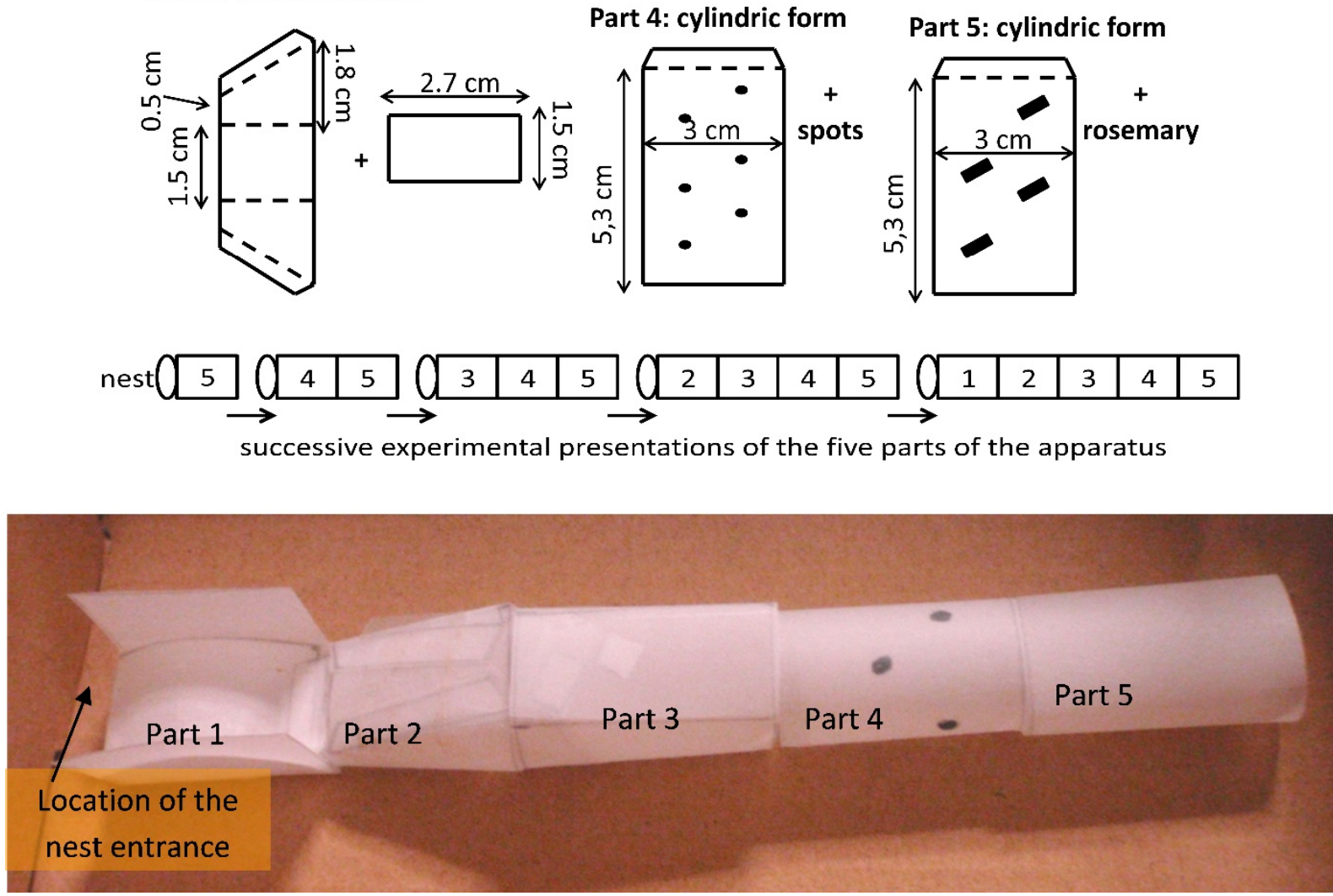

Figure 2. Details of the experimental apparatus $n^{\circ} 2$ which was tied to the nest entrance during the experiment It was made of 5 parts, and was initially presented to the ants as a whole. Then, its part 5 , parts $5+4$, parts $5+4+3$, parts $5+4+3+2$, and finally parts $5+4+3+2+1$, i.e. the entire apparatus, were successively presented. This enabled examining if ants could learn, by using a 'forward chaining' method, the behavioral sequence consisting in correctly navigating the five parts of the apparatus $n^{\circ} 2$ for entering the nest. 

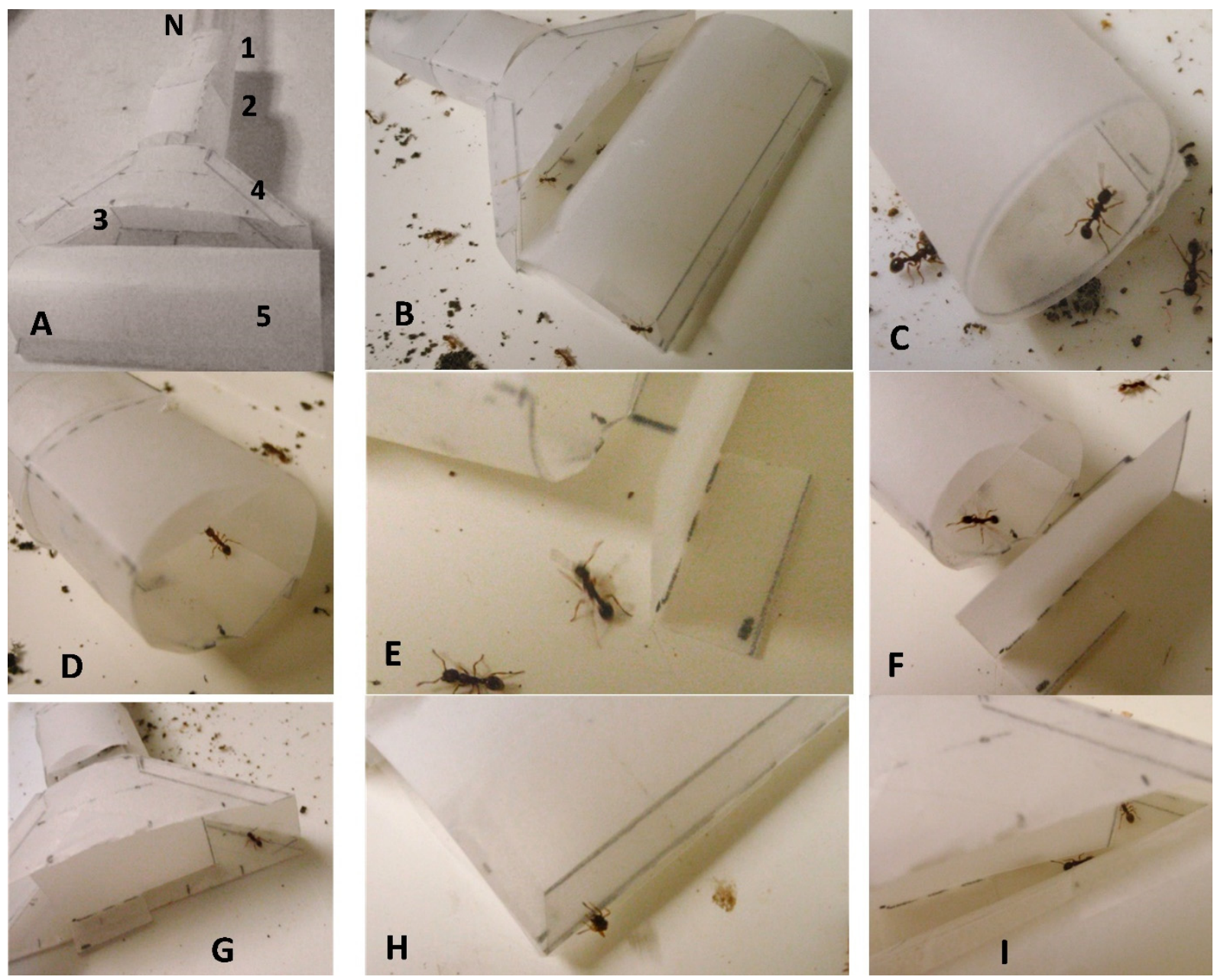

Figure 3. Some views of the apparatus $n^{\circ} 1$ and of the ants' behavior

A: the apparatus tied to the nest entrance $(\mathbf{N}=$ nest entrance). $\mathbf{B}$ : initial presentation of the whole apparatus to the ants which could scarcely navigate it. $\mathbf{C}$ : presentation of part 1 of the apparatus, with an ant already navigating it. D: presentation of parts $1+2$ of the apparatus, with an ant moving through part 2. E: presentation of parts $1+2+3$ of the apparatus, with an ant navigating part 3, i.e. moving round the barrier. F: presentation of parts $1+2+3$ of the apparatus, with an ant having moved round the barrier and presently navigating part 2. G: presentation of parts $1+2+3+4$ of the apparatus, with an ant navigating part 4, i.e. moving through the prismatic form. H: presentation of parts $1+2+3+4+5$ of the apparatus, with an ant starting navigating part 5 , i.e. climbing on the bridge. I: presentation of parts $1+2+3+4+5$ of the apparatus, with two ants having navigated part 5 and presently navigating parts 4 and 3 of the apparatus, i.e. the prismatic form and the barrier. 


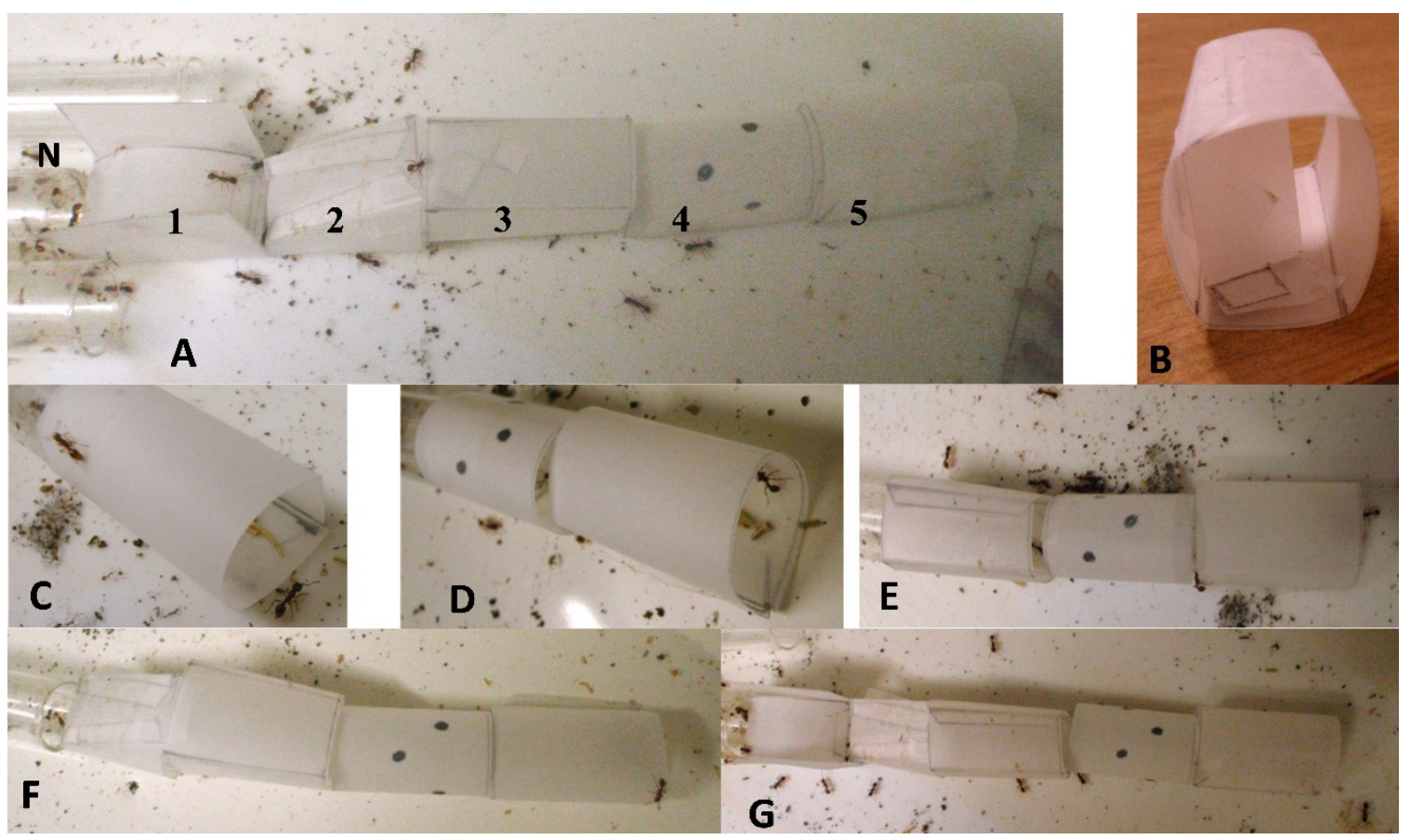

Figure 4. Some views of the apparatus $\mathrm{n}^{\circ} 2$ and of the ants' behavior

A: presentation of the whole apparatus made of 5 parts; this was the initial presentation (N: nest entrance). B: the twist and turn inserted in part 3 of the apparatus. C: presentation of part 5 of the apparatus, with an ant in the nick of entering it. D: presentation of parts $5+4$, with an ant in part 5. E: presentation of parts $5+4+3$ of the apparatus, with an ant entering part 5 and one entering part 3 . F: presentation of parts $5+4+3+2$ of the apparatus with an ant hesitating entering part 5. G: presentation of parts $5+4+3+2+1$ of the apparatus, here with no ant being able to navigate the whole apparatus.

Table 1. First essay of learning a behavioral sequence according to 'backward chaining'

\begin{tabular}{|c|c|c|c|c|c|c|c|}
\hline Presentation of & Colony & np & $\begin{array}{c}\% \text { on } \\
\text { part } 1\end{array}$ & $\begin{array}{c}\mathrm{\%} \text { on } \\
\text { part } 2\end{array}$ & $\begin{array}{c}\text { n on } \\
\text { part } 3\end{array}$ & $\begin{array}{c}\text { n on } \\
\text { part } 4\end{array}$ & $\begin{array}{c}\text { n on } \\
\text { part } 5\end{array}$ \\
\hline \multirow[t]{2}{*}{ all the parts } & $\mathbf{A}$ & 65 & 0 & 0 & 1 & 12 & 10 \\
\hline & B & 77 & 0 & 0 & 0 & 7 & 9 \\
\hline mean $=5.5 \%$ & $\Sigma$ & 142 & 0 & \multirow[t]{2}{*}{0} & 10.7 & $19 \quad 13.4$ & $10 \quad 13.4$ \\
\hline \multirow{2}{*}{ part 1} & $\mathbf{A}$ & 61 & 20 & & & & \\
\hline & B & 23 & \multicolumn{2}{|l|}{6} & & & \\
\hline mean $=30.9 \%$ & $\Sigma$ & 84 & $26 \quad 30.9$ & & & & \\
\hline \multirow{2}{*}{ parts $1+2$} & A & 61 & 13 & 9 & & & \\
\hline & B & 36 & 6 & 9 & & & \\
\hline mean $=19.1 \%$ & $\Sigma$ & 97 & $19 \quad 19.6$ & $18 \quad 18.5$ & & & \\
\hline \multirow[t]{2}{*}{ parts $1+2+3$} & $\mathbf{A}$ & 67 & 6 & 9 & 11 & & \\
\hline & B & 79 & 7 & 12 & 12 & & \\
\hline mean $=13.0 \%$ & $\Sigma$ & 146 & $13 \quad 8.9$ & $21 \quad 14.4$ & $23 \quad 15.8$ & & \\
\hline \multirow{2}{*}{ parts $1+2+3+4$} & $\mathbf{A}$ & 60 & 5 & 9 & 9 & 10 & \\
\hline & B & 49 & 3 & 7 & 9 & 8 & \\
\hline mean $=13.7 \%$ & $\Sigma$ & 109 & $\begin{array}{ll}8 & 7.3\end{array}$ & $16 \quad 14.6$ & $18 \quad 16.5$ & $18 \quad 16.5$ & \\
\hline parts $1+2+3+4+5$ & $\mathbf{A}$ & 109 & 3 & 6 & 8 & 9 & 14 \\
\hline & B & 80 & 1 & 3 & 6 & 13 & 11 \\
\hline mean $=7.8 \%$ & $\Sigma$ & 189 & $4 \quad 2.1$ & $\begin{array}{ll}9 & 4.7\end{array}$ & $14 \quad 7.4$ & $22 \quad 11.6$ & $25 \quad 13.2$ \\
\hline
\end{tabular}

Number (np) of ants on the presented parts of the apparatus $\mathrm{n}^{\circ} 1$, as well as number (n) and proportion (\%) of ants navigating these parts. The first presentation was the 'initial presentation' (line 1), that of the entire apparatus, with all its parts, the part 1 being tied to the nest entrance: the ants succeeded to walk only on the bridge (part 5) and in the prismatic form (part 4). The following presentations were the effective essay of learning the ants to correctly navigate all the parts of the apparatus by successively adding them in the order ' 1 to 5 ' ('backward chaining'). The first column shows that, meanly, $30.9 \%$ of the ants could learn the part 1 of the sequence; $19.1 \%$ could learn the two first parts of the sequence, and so on. Finally, $7.8 \%$ of the ants could learn the whole apparatus. 
Table 2. Second essay of learning a behavioral sequence, according to a 'backward chaining'. Same legend as for Table 1

\begin{tabular}{|c|c|c|c|c|c|c|c|}
\hline Presentation of & Colony & np & $\begin{array}{c}\text { n } \% \text { on } \\
\text { part } 1 \\
\end{array}$ & $\begin{array}{c}\text { n } \% \text { on } \\
\text { part } 2 \\
\end{array}$ & $\begin{array}{c}\text { n } \% \text { on } \\
\text { part } 3 \\
\end{array}$ & $\begin{array}{c}\text { n } \% \text { on } \\
\text { part } 4 \\
\end{array}$ & $\begin{array}{c}\text { n } \% \text { on } \\
\text { part } 5 \\
\end{array}$ \\
\hline \multirow[t]{2}{*}{ all the parts } & $\mathbf{A}$ & 67 & 5 & 6 & 15 & 17 & 7 \\
\hline & B & 38 & 5 & 8 & 9 & 8 & 5 \\
\hline mean $=22.2 \%$ & $\Sigma$ & 105 & $10 \quad 9.5$ & $14 \quad 13.3$ & $24 \quad 22.8$ & $25 \quad 23.8$ & $12 \quad 11.4$ \\
\hline \multirow[t]{2}{*}{ part 1} & $\mathbf{A}$ & 54 & 19 & & & & \\
\hline & B & 56 & 18 & & & & \\
\hline mean $=33.3 \%$ & $\Sigma$ & 111 & $37 \quad 33.3$ & & & & \\
\hline \multirow[t]{2}{*}{ parts $1+2$} & $\mathbf{A}$ & 64 & 14 & 13 & & & \\
\hline & B & 33 & 7 & 15 & & & \\
\hline mean $=23.6 \%$ & $\Sigma$ & 97 & $21 \quad 21.6$ & $28 \quad 28.8$ & & & \\
\hline \multirow[t]{2}{*}{ parts $1+2+3$} & $\mathbf{A}$ & 44 & 5 & 8 & 9 & & \\
\hline & B & 52 & 6 & 9 & 11 & & \\
\hline$m e a n=16.6 \%$ & $\Sigma$ & 96 & $11 \quad 11.5$ & $17 \quad 17.7 \%$ & $20 \quad 20.8$ & & \\
\hline \multirow[t]{2}{*}{ parts $1+2+3+4$} & $\mathbf{A}$ & 48 & 5 & 5 & 8 & 12 & \\
\hline & B & 41 & 4 & 5 & 11 & 19 & \\
\hline mean $=19.4 \%$ & $\Sigma$ & 89 & $9 \quad 10.1$ & $10 \quad 11.2$ & $19 \quad 21.3$ & $31 \quad 34.8$ & \\
\hline \multirow[t]{2}{*}{ parts $1+2+3+4+5$} & $\mathbf{A}$ & 57 & 5 & 6 & 12 & 14 & 10 \\
\hline & B & 55 & 6 & 2 & 10 & 11 & 4 \\
\hline mean $=12.3 \%$ & $\Sigma$ & 112 & 119.8 & $8 \quad 7.1$ & $22 \quad 19.6$ & $25 \quad 22.3$ & $14 \quad 12.5$ \\
\hline
\end{tabular}

All the obtained proportions of ants correctly responding (i.e. navigating the presented parts of the apparatus $\mathrm{n}^{\circ} 1$ ) were higher during this essay than during the first essay (see Table 1). The ants could thus learn the behavioral sequence, but slowly, through an operant conditioning process. More explanations in the text, sections 'Results' and 'Discussion'.

Table 3. Increase of the learning of a behavioral sequence, according to a 'backward chaining', over the 15 minutes of two successive essays, and between these two essays

\begin{tabular}{|c|c|c|c|c|c|c|c|}
\hline \multirow{2}{*}{\multicolumn{2}{|c|}{$\begin{array}{l}\text { Essays } \\
\text { (see Tables 1, 2) } \\
\text { counting periods }\end{array}$}} & \multicolumn{5}{|c|}{$\begin{array}{c}\% \text { of ants successfully navigating the } 2 \text { to } 5 \text { presented parts of the } \\
\text { apparatus and increase of navigating success }\end{array}$} & \multirow{2}{*}{ Mean increase of success } \\
\hline & & \multicolumn{2}{|c|}{ parts: $\quad 1+2$} & \multirow{2}{*}{$\begin{array}{r}1+2+3 \\
8.9 \%\end{array}$} & \multirow{2}{*}{$\frac{1+2+3+4}{6.5 \%}$} & \multirow{2}{*}{$\frac{1+2+3+4+5}{5.2 \%}$} & \\
\hline $\mathbf{I}$ & $0-5$ min & 8.8 & & & & & \\
\hline \multirow{3}{*}{ II } & $10-15$ min & $30 \%$ & $x 3.4$ & $24.3 \% \times 2.7$ & $27.8 \% \quad x 4.3$ & $12.3 \% \quad x 2.4$ & $\begin{array}{ll}x & 3.2\end{array}$ \\
\hline & $0-5 \min$ & 10. & & $9.5 \%$ & $8.5 \%$ & $8.7 \%$ & \\
\hline & $10-15 \min$ & $51.8 \%$ & $x 4.9$ & $26.9 \% \times 2.8$ & $39.0 \% \times 4.6$ & $35.2 \% \times 4.0$ & $\begin{array}{ll}x & 3.1\end{array}$ \\
\hline
\end{tabular}

The proportions of ants correctly navigating the presented parts of the apparatus $\mathrm{n}^{\circ} 1$ during the second essay (II) were higher than those obtained in the course of the first essay (I). Also, each time, the ants better responded over the 5 last minutes than over the 5 first minutes of the apparatus presentation. They learned thus the behavioral sequence, slowly, in the course of each presentation, through some operant conditioning process. More details in the 'Results' and 'Discussion' sections. 
Table 4. First essay of learning a behavioral sequence according to 'forward chaining'

\begin{tabular}{|c|c|c|c|c|c|c|c|}
\hline Presentation of & Colony & np & $\begin{array}{c}n \% \text { on } \\
\text { part } 1 \\
\end{array}$ & $\begin{array}{c}n \% \text { on } \\
\text { part } 2\end{array}$ & $\begin{array}{c}\text { n } \% \text { on } \\
\text { part } 3 \\
\end{array}$ & $\begin{array}{c}\text { n } \% \text { on } \\
\text { part } 4 \\
\end{array}$ & $\begin{array}{c}n \% \text { on } \\
\text { part } 5 \\
\end{array}$ \\
\hline \multirow[t]{2}{*}{ all the parts } & $\mathbf{A}$ & 81 & 4 & 4 & 0 & 3 & 3 \\
\hline & B & 98 & 8 & 9 & 4 & 4 & 5 \\
\hline$m e a n=4.9 \%$ & $\Sigma$ & 179 & $12 \quad 6.7$ & $13 \quad 7.2$ & $4 \quad 2.2$ & $7 \quad 3.9$ & $8 \quad 4.5$ \\
\hline \multirow[t]{2}{*}{ part 5} & $\mathbf{A}$ & 62 & & & & & 12 \\
\hline & B & 78 & & & & & 14 \\
\hline mean $=20.0 \%$ & $\Sigma$ & 130 & & & & & $26 \quad 20.0$ \\
\hline \multirow[t]{2}{*}{ parts $5+4$} & $\mathbf{A}$ & 51 & & & & 2 & 9 \\
\hline & B & 58 & & & & 3 & 13 \\
\hline mean $=12.4 \%$ & $\Sigma$ & 109 & & & & $5 \quad 4.6$ & $22 \quad 20.2$ \\
\hline \multirow[t]{2}{*}{ parts $5+4+3$} & $\mathbf{A}$ & 85 & & & 5 & 5 & 8 \\
\hline & B & 91 & & & 6 & 1 & 3 \\
\hline$m e a n=5.3 \%$ & $\Sigma$ & 176 & & & $11 \quad 6.2$ & $6 \quad 3.4$ & 116.2 \\
\hline \multirow[t]{2}{*}{ parts $5+4+3+2$} & $\mathbf{A}$ & 120 & & 4 & 2 & 1 & 7 \\
\hline & B & 75 & & 3 & 5 & 1 & 2 \\
\hline mean $=3.1 \%$ & $\Sigma$ & 195 & & 73.6 & 73.6 & 10.5 & 94.6 \\
\hline \multirow[t]{2}{*}{ parts $5+4+3+2+1$} & $\mathbf{A}$ & 127 & 6 & 1 & 2 & 1 & 2 \\
\hline & B & 97 & 7 & 1 & 3 & 0 & 0 \\
\hline mean $=2.0 \%$ & $\Sigma$ & 224 & $13 \quad 5.8$ & 20.9 & $\begin{array}{ll}5 & 2.2 \\
\end{array}$ & 10.4 & 20.9 \\
\hline
\end{tabular}

Number (np) of ants on the presented parts of the apparatus $n^{\circ} 2$, as well as number (n) and proportion (\%) of ants navigating these parts. The first presentation was the 'initial presentation' (line 1), that of the entire apparatus with all its parts, the part 1 being tied to the nest entrance: the ants could scarcely navigate the apparatus. The following presentations were the attempt to learn the ants to correctly navigate all the parts of the apparatus by successively adding them in the order ' 5 to 1 ' ('forward chaining'). The first column shows that, meanly, $20.0 \%$ of the ants could learn the part 5 of the sequence; $12.4 \%$ could learn the two last parts of the sequence, and so on. Finally, $2.0 \%$ correctly responded to the entire apparatus, what was a very low score.

Table 5. Second essay of learning a behavioral sequence, according to a 'forward chaining'. Same legend as for Table 4

\begin{tabular}{|c|c|c|c|c|c|c|c|}
\hline Presentation of & Colony & $\mathbf{n} \mathbf{p}$ & $\begin{array}{c}\text { n } \% \text { on } \\
\text { part } 1\end{array}$ & $\begin{array}{c}\text { n } \% \text { on } \\
\text { part } 2 \\
\end{array}$ & $\begin{array}{c}n \% \text { on } \\
\text { part } 3\end{array}$ & $\begin{array}{c}\text { n } \% \text { on } \\
\text { part } 4\end{array}$ & $\begin{array}{c}\text { n } \% \text { on } \\
\text { part } 5\end{array}$ \\
\hline \multirow[t]{2}{*}{ all the parts } & $\mathbf{A}$ & 103 & 6 & 0 & 0 & 1 & 3 \\
\hline & B & 94 & 7 & 2 & 0 & 0 & 2 \\
\hline$m e a n=2.1 \%$ & $\Sigma$ & 107 & $13 \quad 6.6$ & 21.0 & $\begin{array}{ll}0 & 0.0\end{array}$ & 10.5 & $5 \quad 2.5$ \\
\hline \multirow[t]{2}{*}{ part 5} & $\mathbf{A}$ & 65 & & & & & 5 \\
\hline & B & 69 & & & & & 12 \\
\hline mean $=12.7 \%$ & $\Sigma$ & 134 & & & & & $\begin{array}{ll}17 \quad 12.7\end{array}$ \\
\hline \multirow[t]{2}{*}{ parts $5+4$} & $\mathbf{A}$ & 82 & & & & 5 & 5 \\
\hline & B & 56 & & & & 2 & 4 \\
\hline$m e a n=5.8 \%$ & $\Sigma$ & 138 & & & & $7 \quad 5.1$ & $92 \quad 6.5$ \\
\hline \multirow[t]{2}{*}{ parts $5+4+3$} & $\mathbf{A}$ & 59 & & & 2 & 2 & 3 \\
\hline & B & 67 & & & 0 & 1 & 6 \\
\hline mean $=3.7 \%$ & $\Sigma$ & 126 & & & 21.6 & 32.4 & $9 \quad 7.1$ \\
\hline \multirow[t]{2}{*}{ parts $5+4+3+2$} & $\mathbf{A}$ & 70 & & 1 & 0 & 2 & 4 \\
\hline & B & 97 & & 4 & 7 & 1 & 0 \\
\hline mean $=2.8 \%$ & $\Sigma$ & 167 & & $5 \quad 3.0$ & $7 \quad 4.2$ & $\begin{array}{ll}3 & 1.8\end{array}$ & $\begin{array}{ll}4 & 2.8\end{array}$ \\
\hline \multirow[t]{2}{*}{ parts $5+4+3+2+1$} & $\mathbf{A}$ & 66 & 4 & 0 & 0 & 2 & 3 \\
\hline & B & 72 & 2 & 0 & 1 & 2 & 5 \\
\hline mean $=2.7 \%$ & $\Sigma$ & 138 & $\begin{array}{ll}6 & 4.3\end{array}$ & $\begin{array}{ll}0 & 0.0\end{array}$ & $\begin{array}{ll}1 & 0.7\end{array}$ & $\begin{array}{ll}4 & 2.9\end{array}$ & $\begin{array}{ll}8 & 5.8\end{array}$ \\
\hline
\end{tabular}

The obtained proportions of ants correctly navigating the presented parts of the apparatus $n^{\circ} 2$ were lower during this essay than during the first essay (see Table 4). The ants were thus unable to learn a behavioral sequence according to a 'forward chaining' method. Such a result can be explained by the fact that the ants did not went through a sensu stricto operant conditioning process. More explanations in the 'Results' and 'Discussion' sections. 
Table 6. Lack of change in the learning of a behavioral sequence, according to a 'forward chaining', over the 15 minutes of two successive essays, and between these two essays

\begin{tabular}{|c|c|c|c|c|c|c|}
\hline \multirow{2}{*}{\multicolumn{2}{|c|}{$\begin{array}{l}\text { Essay } \\
\text { (see Tables 4, 5) } \\
\text { counting periods } \\
\end{array}$}} & \multicolumn{4}{|c|}{$\begin{array}{l}\% \text { of ants successfully navigating the } 2 \text { to } 5 \text { presented parts of the apparatus and } \\
\text { increase of navigating success }\end{array}$} & \multirow{2}{*}{$\begin{array}{l}\text { Mean increase of } \\
\text { success }\end{array}$} \\
\hline & & parts: $\quad 5+4$ & $5+4+3$ & $5+4+3+2$ & $5+4+3+2+1$ & \\
\hline I & $0-5 \min$ & $9.8 \%$ & $6.2 \%$ & $4.9 \%$ & $4.2 \%$ & \multirow[b]{2}{*}{$\begin{array}{ll}x & 0.64\end{array}$} \\
\hline \multirow{3}{*}{ II } & 10 - 15 min & $10.9 \% \times 1.1$ & $5.4 \% \quad x \quad 0.88$ & $1.7 \% \quad x 0.35$ & $0.9 \% \times 0.23$ & \\
\hline & $0-5$ min & $7.5 \%$ & $3.7 \%$ & $3.8 \%$ & $3.8 \%$ & \\
\hline & $10-15 \min$ & $8.1 \% \times 1.1$ & $4.1 \% \times 1.1$ & $2.7 \% \times 0.71$ & $0.53 \% \times 0.14$ & $\begin{array}{ll}x & 0.76\end{array}$ \\
\hline
\end{tabular}

The proportions of ants correctly navigating the presented parts of the apparatus $\mathrm{n}^{\circ} 2$ during the second essay (II) were lower than those obtained in the course of the first essay (I). Also, each time, the ants responded less well over the 5 last minutes than over the 5 first minutes of the apparatus presentation. They thus did not learn the behavioral sequence, because they did not go through operant conditioning. More details in the 'Results' and 'Discussion' sections.

\section{Results}

\subsection{Apparatus $n^{\circ}$ 1, 'Backward Chaining'}

When the apparatus $n^{\circ} 1$ was presented for the first time to the ants, as a whole and tied to the entrance, the ants could scarcely navigate it. The mean proportion of ants correctly responding equaled $5.5 \%$. After that, when the different parts of the apparatus were successively added and presented to the ants (from part 1 only, until all the five parts in a 'backward chaining' method), the ants could somewhat navigate the presented elements (Table 1). Of course, their ability in doing so decreased when more and more parts were added, because the navigation difficulty increased. Table 1 details the proportion of ants correctly navigating each part of the apparatus during each presentation, as well as the mean proportion obtained at each of these presentations. The final presentation consisted in presenting the five parts of the apparatus as a whole (thus as during the initial presentation), and the five obtained mean proportions of ants correctly navigating each of the five parts were then higher than the five ones obtained during the initial presentation (Table 1 , lines 1 and $6 ; \mathrm{N}=5, \mathrm{~T}=15, \mathrm{P}=0.031$ ). The ants may thus have learned, at least partly, how to navigate the whole apparatus, i.e. the behavioral sequence consisting in moving successively on a bridge, through a prismatic form, around a barrier, through a parallelepiped form and through a cylindrical form.

For checking if ants effectively somewhat learned the proposed sequence and retained something of their learning, a second identical essay was conducted the following day (Table 2). During the initial presentation of that second essay, the ants reached better scores than during the same initial presentation of the first essay $(\mathrm{N}=5, \mathrm{~T}=+14, \mathrm{P}=$ 0.063), and the mean score was higher (Tables 1, 2, first line). Then, during the presentation of one to five parts of the apparatus, the ants reached mean scores higher than those reached during the first essay (Tables 1, 2, first column, lines $2-6 ; \mathrm{N}=5, \mathrm{~T}=15, \mathrm{P}=0.031$ ). Ants have thus learned the behavioral sequence to some extent.

During the first as well as the second essay, for each presentation, the ants' score was higher during the last five minutes of the essay than during the first five minutes $(\mathrm{N}=8, \mathrm{~T}=36, \mathrm{P}=0.004)$. The increase in score between the first and the last five minutes of every presentation pointed out the ants' learning, this increase equaling about 'three times better' (Table 3). Note also that the different scores obtained, during the first and the five last minutes of the presentations, were higher during the second essay than during the first one (Table $3 ; \mathrm{N}=8, \mathrm{~T}=36, \mathrm{P}=$ 0.004).

Such learning can easily be explained by a common operant conditioning. When only the part 1 was presented to the ants, correct navigation of this part allowed ants entering the nest. They were thus rewarded. When parts 2 and 1 were presented, a correct navigation of part 2 allowed the ants reaching the part 1 which is associated with the reward 'entering the nest'. They could thus learn the navigation of part 2, being rewarded by having access to part 1. When the parts 3,2 and 1 were presented, responding to the part 3 allowed the ants reaching the part 2, which is associated to 'reaching part 1', and the part 1 being associated to the reward. The ants learned thus the navigation of part 3. Such an operant conditioning went on for the parts 4 and 5, and was reinforced at each presentation. Ants could thus acquire the ability in performing a behavioral sequence, in fact a 'response chaining', being learned to do so according to a 'backward chaining' (the last act to accomplish being the first learned, the first act to perform being the last learned). In fact, for acquiring this ability, the ants were conditioned thanks to operant conditioning. 


\subsection{Apparatus $n^{\circ} 2$, 'Forward Chaining'}

When the apparatus $n^{\circ} 2$ was presented as a whole to the ants, for the first time, these insects could only scarcely navigate it (Table 4, first line). Thereafter, when the different parts of the apparatus were presented to the ants in a 'forward' chaining (from only the part 5 to finally all the parts), the ants were not able to efficiently navigate the presented parts (Table 4, lines 2 to 6). Their mean scores kept a low value (Table 4, first column). The last presentation was that of the five parts of the apparatus, so of the whole apparatus just like during the initial presentation. The proportions of ants correctly navigating these five parts were not higher than those obtained during the initial presentation; they were even at the limit of being significantly lower (Table 4, line 6 vs line 1 ; N $=4, \mathrm{~T}=10, \mathrm{P}=0.063$ ). The ants seemed thus to be unable to learn correctly navigating the apparatus, i.e. the behavioral sequence consisting in walking through a cylindrical form containing rosemary, a cylindrical form with black spots, a prismatic form with a twists and turns path, a hexahedral form and finally on a bridge. Note that the mean proportions of ants correctly responding during each of the five presentations of the different parts of the apparatus $\mathrm{n}^{\circ} 2$, in a 'forward chaining', were lower than those obtained during the equivalent presentations of the parts of apparatus $\mathrm{n}^{\circ} 1$, in a 'backward chaining' (Table 1 vs 4 , first columns; $\mathrm{N}=6, \mathrm{~T}=-21, \mathrm{P}=0.016$ ).

The present essay was reproduced for examining if ants, finally, could learn something of the proposed behavioral sequence (Table 5). During the initial presentation (i.e. of the apparatus as a whole) of that second essay, the ants' scores of navigation were not higher, but even lower than those obtained during the initial presentation of the first essay (Tables $5 v s$, first lines; $\mathrm{N}=5, \mathrm{~T}=-15, \mathrm{P}=0.031$ ). After that, during the presentation of only the part 5 of the apparatus, then of the parts $4+5,3+4+5,2+3+4+5$, and finally of all the parts of the apparatus, the proportions of ants responding were weak and not higher than those obtained during the first essay (table $5 v s 4$, first column; $\mathrm{N}=5, \mathrm{~T}=-13,+2, \mathrm{P}=0.099)$. Apparently, the ants did not learn during the first essay. The last presentation made during the second essay was that of all the parts of the apparatus, so of the whole apparatus just like during the initial presentation. The ants answered not better than during the initial presentation (Table 5, line 6 vs $1 ; \mathrm{N}=5, \mathrm{~T}=-5,+10, \mathrm{P}=0.313$ ). The ants appeared thus to be unable to learn the behavioral sequence even during a repeated essay. A significant difference existed between the ants' scores obtained during this second essay and those obtained during the second essay made with the apparatus $n^{\circ} 1$ using the 'backward chaining' method ( $N$ $=6, \mathrm{~T}=-21, \mathrm{P}=0.016$ ).

A supplementary proof of the inability of ants in learning the proposed behavioral sequence was furnished by the comparison of the ants' scores presented during the five first and the five last minutes of each presentation (Table 6). The scores presented during the five last minutes were significantly lower than those presented during the first five minutes $(\mathrm{N}=8, \mathrm{~T}=-34,+2, \mathrm{P}=0.012)$, and the 'increase' between the two time periods was less than 1.0, i.e. there was thus no increase of scores during each presentation of the apparatus $\mathrm{n}^{\circ} 2$ according to a 'forward chaining' system.

During each step of the present experiment with the apparatus $n^{\circ} 2$, we observed that ants having navigated a part of the apparatus very often turned back when reaching the next part, and came back inside the previous part of the apparatus. This allowed us to explain the ants' inability in learning a behavioral sequence according to a 'forward chaining' system. After having crossed the part 5 of the apparatus, tied to the nest entrance, the ants may have learned that part since having been rewarded (i.e. having had access to their nest entrance). Confronted to parts 5 and 4 , after having crossed the part 5, the ants were in front of part 4 and not of their nest entrance. They were thus not rewarded. Consequently, not only they were not inclined in going through part 4, but also they somewhat lost their learning of part 5. When confronted thereafter to parts 5, 4 and 3, even if still crossing part 5, they reached then unknown elements and not directly a reward. Therefore, they learned nearly nothing. Such events went on for the subsequent presentations of parts 5, 4, 3,2 and of parts 5, 4, 3,2,1. To learn a behavioral sequence in a 'forward chaining' system, the ants should have used their response to a part of the apparatus as a 'motivation' for going on and making the following step. However, they could not do so. Ants (more exactly M. sabuleti workers) could not acquire a behavioral sequence according to a 'forward chaining' system. They could acquire a behavioral sequence only according to a 'backward chaining' method, because, under that method, they undergo true operant conditioning.

\section{Discussion}

We have thus tried to learn a behavioral sequence to M. sabuleti workers. They could learn the sequence only when being presented with the successive steps of the sequence in a backward order. These ants did not learn under a forward order presentation. As explained in the 'Results' section, this showed that M. sabuleti workers could learn a behavioral sequence only when being rewarded for each correctly exhibited step. Without perceiving any reward, using only their response to a given step for tempting to accomplish the following step, the ants did not learn. 
In nature, the young ants learn to come back to their nest. They do so thanks to a backward method. They first forage in the vicinities of the nest, still perceiving (visually and odorously) their nest entrance, which was the reward. Later, they forage farther from the nest and coming back onto the vicinities of their nest represents a reward. They walk very far from the nest only when being older, going to distant food sites, cemeteries, or a new nest site (M.-C. Cammaerts \& R. Cammaerts, 1980, 2000; Cammaerts, 2017d). We experimentally removed a few young ants from the inside of the nest and set them far from the nest: they never succeeded in re-entering their nest (personal observation). Bees also progressively learn to come back to their hive (Tautz, 2009), to forage around the hive, to fly far from it, in that order, what is, in fine, a backward order providing a reward after each correctly performed step.

The ants' recruitment constitutes a behavioral sequence (Passera \& Aron, 2005). How is it acquired by young ants? The very young ants stay inside of the nest. The middle aged ones do not recruit nesmates, but are recruited by older ones having found a food source. They thus followed for a time a recruiting ant, incited to do so by the attractive fraction of the Dufour gland content emitted by the recruiting ant. The middle aged ants are rewarded for acting in this manner when reaching the food site. Then, after having collected food, they follow the trail laid on the ground by the recruiting ants, and so come back to their nest, what represents another reward. They thus learn the trajectories towards the food, and back to the nest, together with the corresponding social odors, through conditioning. After having exhibited this sequence several times, they can reproduce it, going to the food site emitting their attractive Dufour gland content and coming back to the nest depositing then their trail pheromone on the ground (Passera \& Aron, 2005; Hölldobler \& Wilson, 1990). The same reasoning is valid for the ants' learning nest relocation.

In our studies of ants' solving problems (Cammaerts, 2017a), reacting as never before in novel situations (Cammaerts, 2017b), using tools (Cammaerts, 2018), each time the ants succeeded in correctly reacting, they were somewhat rewarded. In the same way, each time the ants did not succeed in correctly responding, they received no reward. We can thus definitively conclude that ants (or more precisely the ant $M$. sabuleti) learn a behavioral sequence, as well as any other new behavior, only when being rewarded at each step of their learning. It should be interesting to reproduce this experimentation on other $M$. sabuleti colonies (since differences exists between colonies), and to examine what is the situation for other ant species, as well as for other social hymenoptera such as bees and bumblebees which are known to valuably learn through classical and operant conditioning (Menzel \& Mercer, 2012; Dyer \& Chittka, 2004).

The facts are sometimes similar, sometimes different for evolved mammals and birds. Cats learn to hunt thanks to imitation and operant conditioning (Leyhausen, 1979). A cat having never seen its mother hunting, having never had the occasion to try hunting, cannot hunt when being old. Lions as other mammals, as well as chimpanzees, also learn to hunt being trained in a backward order while they are young: they are firstly in contact with dead prey they can eat, then with collected living prey, and finally with potential alive prey (Aron \& Passera, 2009). Such learning also allows young black-headed gulls acquiring their specific hunting technique (Aron \& Passera, 2009). Serial learning according to a backward order has been shown to allow monkeys, as well as parrots, learning a behavioral sequence (Camps, Castéras, \& Mélan, 2002). On the basis of the above information, the evolved mammals and birds' learning appears similar.

Parrots are able to learn a whole behavioral sequence more rapidly than when learning the sequence step by step according to a strictly 'backward chaining'. They can anticipate, they can guess the 'planning' of a sequence, and they can thus learn it nearly as a whole, or in a forward order (Sherwood, Klandorf, \& Yancey, 2016). When learning in this manner, the stimulus going off a given act is simply the accomplishment of the previous act. Of course, humans can learn according to this method, submitted to a forward presentation of the successive acts of a sequence. There is a restriction: very young children better learn through a backward presentation of the successive items, and intellectually deficient humans can learn a sequence only when trained according to a backward order presentation of the successive steps to be learned (Rouchouse, 1981).

\section{Conclusion}

To conclude, on basis of our studies on ants and of other researchers' published results on evolved mammals and birds, we can state that Myrmica sabuleti ants can learn a new behavior - a sequence, a technique, a given reaction - only when reasonably rewarded all along their learning. They are thus, in this domain, maximally as capable as the youths of evolved mammals and birds, but less capable than the adults of some of these evolved vertebrates which can learn a sequence by seeing, memorizing and then imitating the successive acts. 


\section{References}

Aron, S., \& Passera, L. (2009). Les sociétés animales: Évolution de la coopération et organisation sociale. Bruxelles, De Boeck Université. Retrieved from https://books.google.be/books?isbn=280412861X

Balleine, B. W., Garner, C., Gonzalez, F., \& Dickinson, A. (1995). Motivational control of heterogeneous instrumental chains. Journal of Experimental Psychology: Animal Behavior Processes, 21, 203-217. Retrieved from psycnet.apa.org/record/1995-35848-001

Cammaerts, M.-C. (2013). Sensu stricto individual conditioning, and imitation, in the ant Myrmica sabuleti (Hymenoptera, Formicidae). Annales of the Entomological Society of France, 49, 402-412. http://dx.doi.org/10.1080/00379271.2014.893679

Cammaerts, M.-C. (2017a). Ants' ability in solving simple problems. International Journal of Biology, 9(3), 26-37. https://doi.org/10.5539/ijb.v9n3p26

Cammaerts, M.-C. (2017b). In a novel situation, ants can learn to react as never before - a preliminary study. Journal of Behavior, 2(2), 1011. Retrieved from https://www.jscimedcentral.com/Behavior/behavior-2-1011.php

Cammaerts, M.-C. (2017c). Cognitive differences between conspecific ant colonies. Journal of Behavior, 2(1), 1005, 12p. Retrieved from https://www.jscimedcentral.com/Behavior/.../behavior-2-1005.pdf

Cammaerts, M.-C. (2017d). Some new information on ants' cemeteries organization. Asian Journal of Biology, 2(1), $1-10$.

Cammaerts, M.-C. (2018). Can Myrmica rubra ants use tools or learn to use them? International Journal of Biology, 10(1). URL: https://doi.org/10.5539/ijb.v10n1p1

Cammaerts, M.-C., \& Cammaerts, D. (2014). Comparative outlook over three Myrmica species' biotopes and foragers' know-how. Biologia, 69, 1051-1058. Retrieved from https://link.springer.com/article/10.2478/ s11756-014-0399-z

Cammaerts, M.-C., \& Cammaerts, R. (1980). Food recruitment strategies of the ants Myrmica sabuleti and Myrmica ruginodis. Behavioural Processes, 5, 251-270. https://doi.org/10.1016/0376-6357(80)90006-6

Cammaerts, M.-C., \& Cammaerts, R. (2000). Nest odour in the ant Myrmica rubra (Myrmicinae). Biologia, 55, 509-523. Retrieved from https://www.cabdirect.org/cabdirect/abstract/20003026580

Cammaerts, M.-C., \& Cammaerts, R. (2015a). Ontogenesis of ants' cognitive abilities (Hymenoptera, Formicidae). Advanced Studies in Biology, 7, 335-348 + synopsis: 349-350. http://dx.doi.org/10.12988/asb.2015.54241

Cammaerts, M.-C., \& Cammaerts, R. (2015b). Are ants (Hymenoptera, Formicidae) capable of self recognition? Journal of Sciences, 5(7), 521-532. Retrieved from http://difusion.ulb.ac.be/vufind/Record/ ULB-DIPOT:oai:dipot.ulb.ac.be:2013/219269/Details

Cammaerts, M.-C., \& Cammaerts, R. (2016a). Spatial expectation of food location in an ant on basis of previous food locations (Hymenoptera, Formicidae). Journal of Ethology, 1-9, https://doi.org/10.1007/s10164 $-016-0494-4$

Cammaerts, M.-C., \& Cammaerts, R. (2016b). Ants can expect the time of an event on basis of previous experiences. ISRN Entomology. https://doi.org/10.1155/2016/9473128

Camps, J.-F., Castéras, V., \& Mélan, C. (2002). Mécanismes d'apprentissage sériel chez les vertébrés. L'année psychologique, 102, 747-774. Retrieved from www.persee.fr/doc/psy_0003-5033_2002_num_102_4_29618

D’Amato, M. R., \& Colombo, M. (1988). Representation of serial order in monkeys. Journal of Experimental Psychology: animal behavior processes, 14, 131-139. Retrieved from https://www.ncbi.nlm.nih.gov/ pubmed/3367099

Dyer, A. G., \& Chittka, L. (2004). Fine colour discrimination requires differential conditioning in bumblebees. Naturwissenschaften, 91, 224-227. Retrieved from https://www.ncbi.nlm.nih.gov/pubmed/ 15146269

Hölldobler, B., \& Wilson, E. O. (1990). The ants. Berlin. Springer Verlag. Retrieved from www.springer.com/gp/book/9783540520924

Leyhausen, P. (1979). Cat behavior: the predatory and social behavior of domestic and wild cats. New York: Garland STPM Press. Retrieved from https://www.abebooks.com/book.../cat-behavior.../paul-leyhausen/ 
Menzel, R., \& Mercer, A. (2012). Neurobiology and Behavior of Honeybees. Berlin Heeidelberg, Springer-Verlag. Retrieved from https://books.google.be/books?isbn=364271496X -

Passera, L., \& Aron, S. (2005). Les fourmis : comportement, organisation sociale et évolution. Ottawa, Canada, Les Presses Scientifiques du CNRC. Retrieved from https://books.google.be/books?isbn=066097021X

Pearce, J.M. (2008). Animal learning and cognition, an introduction. East Sussex, USA, Canada. Psychology Press. Retrieved from http://www.worldcat.org/title/animal-learning-cognition-an-introduction/oclc/682223995

Rouchouse, J.-C. (1981). Ethologie humaine. Analyse des situations de contacts entre enfants de six à trente mois. Enfance, 4-5, 271-288. Retrieved from www.persee.fr/doc/enfan_0013-7545_1981_num_34_4_2764

Sherwood, L., Klandorf, H., \& Yancey, P. (2016). Physiologie animale. Bruxelles, De Boeck Université. Retrieved from https://books.google.be/books?isbn=2807302866

Siegel, S., \& Castellan, N.J. (1989). Nonparametric statistics for the behavioural sciences. Singapore, McGraw-Hill Book Company. Retrieved from https://www.amazon.com/Sidney-Siegel...Statistics.../ B008WDIR6...

Tautz, J. (2009). L'étonnante abeille. Science, De Boeck Supérieur, 2009. Retrieved from https://books.google.be/books?isbn=2804101312

Terrace, H. S. (1986). A noverbal organism's knowledge of ordinal position in a serial learning task. Journal of Experimental Psychology: Animal Behavior Processes, 12, 202-214.

Terrace, H. S. (1987). Chunking by a pigeon in a serial learning task. Nature, 325, 149-151. Retrieved from www.nature.com > nature > letters

Thvedt, J. E., Zane, T., \& Walls, R. T. (1984). Stimulus functions in response chaining. M J Mental Deficit, 88(6), 661-667.

\section{Copyrights}

Copyright for this article is retained by the author(s), with first publication rights granted to the journal.

This is an open-access article distributed under the terms and conditions of the Creative Commons Attribution license (http://creativecommons.org/licenses/by/4.0/). 